\title{
CHALLENGES AND OPPORTUNITIES OF ASYNCHRONICITY: TASK-BASED APPROACH AFTER COVID-19
}

\author{
Līga Beḷicka, Tatjana Bicjutko \\ University of Latvia, Latvia
}

\begin{abstract}
The fast transition to fully online studies due to the pandemic made the universities around the world question many of their accepted notions on teaching foreign languages in general and English for Specific Purposes (ESP) methodology in particular. Putting stress on the synchronous remote teaching and learning has proven to yield a reductionist perspective missing asynchronicity, the dimension which makes reconsider the whole educational process.

With its shift from the sole focus on learning terminology to training skills in authentic professional contexts, the task-based approach has long excelled in meeting the diverse needs of students. Thus, the research question is how well task-based teaching (TBT) solves the problems raised with asynchronous learning in a university ESP course. The research of available literature on TBT yielded the framework for constructing an extended task applicable in the advanced medical English. The case study with 120 first-year students of medicine organised around an informational interview with health professionals demonstrated easy adaptability of the task to the asynchronous nature of the educational process. Personal observations by the course instructor, summaries of student-conducted interviews, and student written feedback proved the responsiveness of the method to the learners' needs and the potential of the approach in terms of motivation. The emphasis on self-directed learning, however, threatens the systematicity of the acquired language skills, as a more controlled teaching environment would not allow "skipping" any learning step. Additionally, TBT does not solve the problem of the voluminous teaching load.
\end{abstract}

Keywords: asynchronicity, collaboration, English for Specific Purposes, extended task, informational interview, Task-Based Approach.

\section{Introduction}

As the COVID-19 pandemic made universities around the world shift to fully remote studies, foreign language teaching faced an unparalleled challenge. In the lockdown situation, the technical solutions were the first to seek for, but technology is not teaching, and preparedness of teaching 
personnel proved to be an even more serious matter. Furthermore, the rapid transition foregrounded many pending issues, including concerns in respect of English for Specific Purposes (ESP) methodology.

The emergency digitalisation raised a question of rationalising the needs of education as transposed in a remote context. Gathering early response, the IAU Global Survey on the impact of COVID-19 on higher education around the world (International Association of Universities [IAU], 2020) showed that only $2 \%$ of their respondents reported teaching and learning as not being affected by the pandemic, with more than half of those "immune" being virtual universities. The courses on using online teaching tools were offered to cover the gap, but the inability to shift easily "often resulted in 'learning by doing' approaches or attempting to imitate what would have been the face-to-face way of proceeding, yet using distance mode" (IAU, 2020, p. 25). So, the stress was put on the synchronous remote teaching and learning, thus, leaving the asynchronous in the margins. In other words, face-to-face activities were simply transferred online, and the focus on individual learning assessment, which so far had been (and still is) a prevailing mode in higher education, logically led to implementing additional written assignments and leaving the capacity of digital tools outside of virtual classroom unexploited. Such an approach is by no means reductionist, as focused attention to asynchronicity may significantly enrich the whole educational process. Thus, the paper examines the potential of asynchronous activities in the context of university ESP courses.

The topicality of the study is in its attempt to offer some methodology capable to stand up to the challenges of asynchronous learning, the list of which was well put by the Director of the Cambridge University Language Programmes Nebojša Radić (2020) and comprised among other things the mode of delivery, application of technology, philosophy, communication patterns, diversity, student support, and management structure. In turn, the challenges of asynchronous online learning may result in isolation, risk of apathy, lower level of retention and higher dropout rates, with the latter two being particularly dramatic in the university context.

\section{Asynchronicity and collaboration}

Rooting in Greek, asynchronous may translate as "not together with time" ("asynchronous" "syn-" 2010), which gives a better perspective of the concept than its accepted definition of "not occurring at the same time" and refers to signals or events that occur at random instants and/or intervals. Another insight may come from programming, where synchronously running codes stop any other codes, whereas asynchronously running codes do not block other codes from running. By analogy, synchronous learning 
happens in real time, whereas asynchronous learning happens on one's own schedule, offers more flexibility, but requires tighter planning.

The existing research into teaching approaches to match the potential of technology-enhanced instruction has demonstrated the possibility of successful collaborative learning in an asynchronous networked environment (Wang, 2010) and confirmed the feasibility of authentic work through the integration of student-directed research, writing-based tasks, and interactive assignments (Darling-Aduana, 2021). Creation and maintenance of collaboration through the Community of Inquiry were marked as providing an online educational environment enabling ESL students to improve their English language proficiency (e. g., Herrera Díaz \& González Miy, 2017; Wu et al., 2017) and users of Global Englishes (GE) to engage in learning and construction of knowledge (Smidt et al., 2021).

Furthermore, taking place synchronously or asynchronously through the Internet, computer-supported collaborative learning (CSCL) is maintained by sharing and construction of knowledge among participants and is not reducible to individual learning (Stahl et al., 2006). Thus, to exercise the potential of collaborative learning to its fullest, student engagement in mediating ideas is paramount, and the level of transactivity, or learning by acting on each other's reasoning (Teasley, 1997), is a quality indicator of success (Weinberger \& Fischer, 2006). Conducted remotely and happening both synchronously and asynchronously, transactive interactions should be carefully guided and may be fostered by discussion scripts (Lazareva, 2021; Noroozi et al., 2012; Vogel et al., 2017 ). In the absence of programming support, CSCL scripts may be exchanged for elaborated instructions marking each consecutive step and including both independent and collaborative activities. The explicitness of step-by-step instructions is corroborated by the action-oriented task-based approach (TBA) (Ellis, 2015), which is to be discussed next in the context of ESP at the tertiary level.

\section{ESP and task-based approach}

The current uncertainty around ESP courses is caused by multiple factors, among which numerous groups of highly motivated, advanced students and outdated methodology are arguably most important. Among the certainties, however, is the need in students' exposure to professional environments and developments outside academia, with the move to fully online studies significantly problematising the situation.

Initiated in the 1980s, the task-based approach grew out of the needs of communicative language teaching and has been practiced in teaching English for Specific Purposes (ESP) at universities since its inception. Helping to organise the language education process "as the progressive transmission of stable truth" (Kramsch \& Vinall, 2015, p. 14), the task-based 
approach has demonstrated its high adaptability in general and to the digital milieu specifically. In fact, with its ad hoc use of focused tasks, task-based teaching (TBT) is claimed to work better online than in a classroom (Ellis, 2020). Being more conducive for incidental acquisition, this learner-centred approach encourages students to be more active in taking bigger control over discourse.

Furthemore, any task is a workplan satisfying four criteria, namely, a primary focus on meaning, existence of an information gap, a clear communicative outcome and incentive to choose linguistic and non-linguistic resources needed to complete the task (Ellis, 2017, 2020). According to Ellis (2020), different classes of learners demand different types of tasks, the array of the latter may be systematised through a set of binary oppositions such as real life vs pedagogic, input-based vs output-based, closed vs open, here-and-now vs there-and-then, focused vs unfocused, and teacher generated vs learner generated tasks. University students simultaneously fall into two categories of advanced and special purpose learners. For such groups, most suitable are output-based, real-life and open there-and-then tasks. Next, whereas for advanced learners an occasional introduction of focused tasks adapted to their needs is required, ESP learners are in need of inputbased content-relevant tasks providing for their adequate functioning in a particular target domain (Long, 1985, p. 91; see also Long, 2015, p. 88).

So, with its shift from the sole focus on learning terminology to training skills in authentic professional contexts, the task-based approach has long excelled in meeting the diverse needs of various groups of learners. Thus, the research question is how well TBT solves the problems raised with asynchronous learning in a university ESP course.

\section{Method}

\section{Context}

The case study was organised with 120 first-year students from the Faculty of Medicine at the University of Latvia, with one of the researchers being the instructor and a participant observer as such. The ESP course syllabus comprises the introduction into academic reading, work on medical terminology and two individual reading assignments, and the final assignment of interviewing a medical professional. In general, the task of conducting an informational interview is essential for finding out more about the type of industry, company, or role the interviewer is interested in. Speaking to someone directly gives students an opportunity to test their assumptions even if they may initially think they already know all about a certain position (Clark, 2015). In the researched case, the timing is paramount as the end of the semester is the moment when students 
have already experienced the actual difficulty of medical studies and may start questioning the appropriateness of their career choice. Thus, the aptly framed interviewing task may become authentic work going beyond the narrow context of language studies.

\section{Task}

The conducted research of available literature on TBT helped to formulate the framework for creating an extended task (Ellis, 2015) applicable in teaching advanced medical English. Organised around the process of interviewing a medical professional, the task cycle consisting of pre-task, task and post-task was built according to the four principles of TBT.

The assignment incorporated several steps of micro-evaluation, with a series of pre-tasks including brainstorming the list of questions, relevant terms and consolidation on the basics of interviewing. After this, the actual interview was conducted with a medical practitioner of the student's choice in the language available to both parties, and then written answers to each of the selected questions were summarized in English. The following post-tasks comprised the reflective phase at which students provided feedback on the peers' interviews, reflected on the whole procedure as a group and individually, watched the three filmed in-depth interviews one of the students had voluntarily filmed, praised the respective interviewees (i. e. doctors) by specifying and detailing their successful performance. The task emphasis on praise intended to encourage the students to focus on the subject matter rather than their mistakes. Both the communication of the interview results and documentation of the process took place in English as requested.

\section{Research procedure}

Employing a qualitative approach, this study sought to understand how well TBT solves the problems raised with asynchronous learning in a university ESP course as the given assignment being performed by students according to their self-selected schedule and using messaging and other means of asynchronous communication when performing the bigger part of the extended task. To answer the research question, the current study used student written feedback comprising summaries of conducted interviews and answers to reflection questions. To check the credibility of findings, the observation and field notes made by the instructor throughout the course were used.

Due to the pandemic situation, the collection and analysis of data happened remotely. The students gave the instructor/researcher their permission for the anonymous use of the data of their feedback as well as her notes taken during their focus groups for research. 
First, the multiphased content analysis of students' feedback on the completed task was performed. The selection of keywords and semantic fields for identification in the corpus was guided by Radič' framework (2020), and they comprised such concepts as time, tools, communication, collaboration, instructions, self-actualisation and personal growth. Out of the seven questions of the guided feedback, the analysis was conducted on the answers to only two questions in the questionnaire, and they were "Would you recommend other students to conduct such an interview?" and "What would you do differently next time?" Of the total 120 participants, only 53 respondents voluntarily posted their answers to the shared Google sheets document specially designed for the purposes of the research; thus, the resulting corpus comprised 53 answers to the two questions each (4,489 words in total). The units identified in the corpus subsequently underwent qualitative analysis. The results of the content analysis were further validated by the observation notes taken in passive participation in small group online student discussions after their submission of the assignment.

The provisions to maintain the confidentiality of research data were implemented, including the retention of the collected data without any identifiers and keeping individual participation anonymous. The collected data were stored in password-protected computers and accessible solely to the researchers.

\section{Results}

As the study aimed at exploring how well task-based teaching (TBT) solves the problems raised with asynchronous learning in a university ESP course, further the results of the content analysis and its validation are presented in line with the methodology described above. It must be noted that when presenting the results, the original language of the students' answers is retained.

The topic of time was the most frequently touched upon in the answers the students provided. Although determined by the structure of the second question, next to pure formal reference in approximately half of the cases, the other half suggested a certain willingness to practice interviewing under a different set of conditions and/or proceed with English language skill development. In line with this, students juxtaposed "this time" and "next time" to indicate that they were interested in processing the material produced by the group in pre-tasks but not included in the final list of their interview questions.

The second most common use of time referred to the COVID-19 period as a challenge and mostly addressed the specific situation in the medical field which students had become aware of when accessing doctors. The 
lack of time medical professionals had due to the pandemic caused students' respect and certain discomfort in proceeding with interview arrangements under such restrictions. Individual mentions of time-related issues concerned the ability to conduct the interview only at night and in early morning hours during the doctor's shift; occasionally an interview was taken outside the doctor's work hours. Students were also concerned of giving interviewees "time to ponder over the answers" which might suggest the level of students' engagement with the task.

Another big topic in relation to the concept of time was students' own lack of time and time management issues raised in group work. Related was the complaint that the interview task was assigned at the end of the semester [in fact, in the middle of November 2020] when the students' workload had already accumulated.

Under the effective epidemiological restrictions, the discussion of digital tools in general and different ways of conducting an interview in particular had a lot of prominence in the provided feedback. The emphasis was on the need for a face-to-face interaction or at least a video session, though some students had decided to interview doctors over a phone (which was also marked as an individual achievement), via messaging (Whatsapp, Facebook Messenger) or even by writing the questions on the paper. In some cases, the choice of interviewing tool/method defined the level of personal confidence in communicating ("I highly doubt I'd see the interviewee in person, but if my confidence could be boosted in future, I'd like to see the interviewee face to face"). One student observed that without seeing the interviewee "I think some of the context for the answers was lost". Not meeting face-to face and communicating through Whatsapp messages was mentioned as an obstacle to group work too.

Concerning communication patterns, most students reported improvement of their communication skills in general and in some cases specifically professional communication skills. There were also several cases when students admitted having learnt new terminology. In several responses, students also emphasized the role of preparation ("I would plan my questions better") in conducting a smooth and successful interview.

Next, mentioning diversity in the feedback, students mostly related it to the work mode, i. e. group work vs individual one, with supporters for both types. The diversity in character traits transpires in the identification of both student and interviewed doctor as introverts or "not very sociable" personalities, whereas the opposite referred to the interviewee only, the one who "wanted to tell me everything". The other binary oppositions met among the answers are young and experienced as well as a relative ("practice such journalistic skills with close people") and a stranger, with the benefits found in each case. There was also a diversity of doctor 
specialisations and the contrast between "interviewing a doctor, [whose] speciality is interesting or from [the] field you want to study in the future" and the one who was simply available for interviewing.

In relation to group work, there were students who would have liked to choose their group based on existing friendships ("Working in a group with unfamiliar people slowed down the progress"). Others, however, found that "work in a group made a studying routine a bit more entertaining". In several answers students pointed out that sharing and comparing answers of different doctors to the set of questions was interesting. In a couple of answers, the same was said about working in groups on preparing the questions for the interview: "everyone had their own idea about what the questions should be".

Concerning management issues discussed in the feedback, there are two prominent topics apart from group settings and time management discussed above. Firstly, it is the provided instructions, which students found "rather complicated [...] for the structure of put out [the set] requirements" and "at first it was hard to understand the steps". And "after going through step by step I finally made it all done." During the focus group discussions the students frequently referred to the way they had followed the hints and how the hints had been helpful had assisted in the task completion. Another, quite an interesting aspect concerned the settings of the interview. Those students, who had managed to visit their doctors at the place of practice, were obviously happier about the overall experience and others mentioned hospital as a desirable place where they would like to complete such an assignment not only because of their interest in the authentic context, but also to conduct the interview "in a hospital or other environment so that the doctor I interview would feel more comfortable". The students' responses show that they were able to cope with a complex seven-step task in the expected degree of detail and were aware of the needs of the interviewee during the interview, which had been one of the issues addressed in the pre-tasks.

For the purposes of this paper, Radič' (2020) global competition and marketing skills are looked upon in the context of students' personal growth, which was another very frequently and emotionally mentioned topic in students' feedback. Students referred to gaining experience in conducting interviews both in a narrow sense of local experience and in a broader sense, i. e. as a moment of overcoming their communication anxiety ("benefit was that I had to get over my fear of talking over the phone and social anxiety in general" "although, it was awkward and uncomfortable I was able to get over my fear of talking with people" "I also got out of the comfort zone and asked questions, led a discussion that is not so easy, especially about medicine, where the person you are interviewing is a 
professional"), gaining confidence through overcoming difficulties ("it can be useful in order to deal with some difficulties" "It [...] gave me encouragement" and showed "what kind of things you should pay more attention to to get there and become the best version of yourself"), drawing professional inspiration and confidence in the correctness of the chosen field ("[the doctor's answer] made me happy, because for a minute I thought that I am thinking like a doctor already" "we talked about doctor profession as a professional colleague" "it can help you to understand if you want to do this job" "makes me want to learn more for myself not for good grades or because professors say"), managing their thinking process and arriving at new insights ("chance to practise planning my thoughts to get to a certain result" "I did not realize how important is the practice itself in real-life situations" "communicating with groupmates raised in me new questions and viewpoints on problems"). Several students admitted that in addition to the questions selected in the group, they had asked questions that interested them personally, which was also implicitly expected after the list of questions had been finalised. In fact, the set was meant to become the backbone of students' semi-structured interview, but it was a difficult idea for some learners to grasp. Finally, one student presented general philosophical insight on addressing difficult issues: "The interview is a great opportunity to get to know about things you were afraid to ask, I would recommend other students not to be afraid of asking some [certain] questions (not only as part of the interview)".

However, for some students, the challenge turned out to be excessive: "I understand that work in group is an important skill, but it wasn't easy for me." Other difficulties mentioned also concerned the level of anxiety and the difficulty to find doctors as well as the time-consuming assignment. Students emphasized the need for more specialised interviews, suggested conducting interviews in pairs and complained about the unequal distribution of work in groups. No language barriers were cited in the examined corpus.

\section{Discussion}

Analysing the findings listed above, it becomes clear that the use of time related concepts testifies to an on-going self-reflection of students' on their performance during the interview. By its very nature, the bigger portion of the task is to be conducted asynchronously, thus, making students take into account real-life restrictions and limitations. Moreover, the evidence is for positive correlation in collaboration between the teacher and students and interview success as well as transactive interactions among students and raising the efficiency of completing the task. Further, the task led students 
into thinking about the role of technologies and routine choices in communication when working asynchronously as well as raised their awareness of the diversity of communication styles.

The discussion around the topic of diversity revealed that in asynchronous learning students are left all by themselves with their own choices, thus, the degree of the recommended autonomy has to be monitored. As seen above, on the one hand, group support is a helpful tool to prevent isolation and stimulate skill development and knowledge acquisition, on the other hand, it may also become overwhelming due to unequal distribution of work and/or inability to cope with choices made by their group.

The students' answers show that various issues related to fears and lack of confidence can be successfully addressed through asynchronicity as there the necessary scaffolding is present. Besides, having arrived at these individual insights, they are able to contribute to the diversity of opinions in their groups. Overall, the task provides for ecological validity and students have ample opportunities to act close to an authentic professional environment.

Summing up the results of the qualitative research, there was hardly any mention of language acquisition per se. However, as TBT is focused on meaning making, logically, learning ESP, students are mainly focusing on the communicative goal rather than a foreign language for its own sake.

Thus, the results of the study demonstrate that TBT mostly helps to overcome the problems raised with asynchronous learning in a university ESP course. However, detailed step-by-step instructions and tutor involvement are necessary to ensure successful task completion.

\section{Conclusions}

The analysis of the bulk of evidence received through content analysis of the student feedback allows to draw the following conclusions:

- the instructor/researcher's observation notes on the case study organised with 120 first-year students of medicine and substantiated by 53 student feedback submissions demonstrated easy adaptability of the task to the asynchronous nature of the educational process;

- the method is responsive to the learners' needs and has a high potential in increasing students' motivation;

- the emphasis on self-directed learning may endanger the systematicity of the acquired language skills; therefore, a more controlled teaching environment is beneficial as it would not allow "skipping" any learning step.

- the success of the assignment depends on tight guidance, with guided instruction carefully worked out and piloted in advance; 
- as of now, TBT does not solve the problem of the voluminous teaching load;

- future assistance might be provided through the introduction of CSCL scripts, whose presence will allow for more flexibility in combining students from different though related fields.

\section{References}

Asynchronous. (n. d.) Random House Kernerman Webster's College Dictionary. (2010). https://www.thefreedictionary.com/asynchronous

Clark, D. (2015). Stand Out Networking: A Simple and Authentic Way to Meet People on Your Own Terms. Penguin.

Darling-Aduana, J. (2021). Authenticity, engagement, and performance in online high school courses: Insights from micro-interactional data. Computers \& Education, 167, 104175, ISSN 0360-1315. https://doi.org/10.1016/j.compedu.2021.104175

Ellis, R. (2015). Understanding second language acquisition, $2^{\text {nd }}$ edition. Oxford: Oxford University Press.

Ellis, R. (2017). Position paper: Moving task-based language teaching forward. Language Teaching, 50 (4), 507-526.

Ellis, R. (2018). Reflections on task-based language teaching. Bristol: Multilingual Matters.

Ellis, R. (2020). Using tasks in language teaching. Cambridge Live Experience, 8-10 September 2020. Cambridge University Press ELT. https://www.youtube.com/ watch?v $=$ jsBTQgE8uhw

Herrera Díaz, L. \& González Miy, D. (2017). Developing the oral skill in online English courses framed by the Community of Inquiry, Profile - Issues in Teachers' Professional Development, 19 (1), 73-88.

International Association of Universities [IAU]. (2020). IAU Global Survey on the impact of COVID-19 on higher education around the world. https://www.iau-aiu.net/IMG/pdf/ iau_covid19_and_he_survey_report_final_may_2020.pdf

Kramsch, C. \& Vinall, K. (2015). The cultural politics of language textbooks in the era of globalization. In Curdt-Christiansen, Xiao Lan \& Csilla Weninger (eds.). Language, Ideology and Education (pp. 11-28). London: Routledge.

Lazareva, A. (2021). Role Scripting as a Tool to Foster Transactivity of Asynchronous Student Discussions. International Journal of Online Pedagogy and Course Design (IJOPCD), 11(3), 1-16. https://www-igi-global-com.datubazes.lanet.lv/gateway/article/279098

Long, M. (1985). A role for instruction in second language acquisition: Task-based language teaching. In K. Hyltenstam \& M. Pienemann (eds.), Modelling and assessing second language acquisition (pp. 77-100). Clevedon: Multilingual Matters.

Long, M. (2015). Second Language Acquisition and Task-Based Language Teaching. Malden, MA: Wiley-Blackwell.

Noroozi, O., Teasley, S. D., Biemans, H. J. A., Weinberger, A., \& Mulder, M. (2012). Facilitating learning in multidisciplinary groups with transactive CSCL scripts. International Journal of Computer-Supported Collaborative Learning, 8, 189-223. https:// doi.org/10.1007/s11412-012-9162-z 
Radič, N. (2020). The language teaching paradigm shift. QS Subject Focus Summit Modern Languages and Linguistics.

Smidt, E., Chau, M. H., Rinehimer, E., Leever, P. (2021). Exploring engagement of users of Global Englishes in a community of inquiry, System, 98, 102477, ISSN 0346-251X. https://doi.org/10.1016/j.system.2021.102477

Stahl, G., Koschmann, T., \& Suthers, D. (2006). Computer-supported collaborative learning: An historical perspective. In R. K. Sawyer (Ed.), Cambridge handbook of the learning sciences (pp. 409-426). Cambridge, UK: Cambridge University Press.

syn. (n. d.) Random House Kernerman Webster's College Dictionary. (2010). https://www. thefreedictionary.com/syn

Teasley, S. D. (1997). Talking about reasoning: How important is the peer in peer collaboration? In Resnick L. B. (Ed.), Discourse, tools and reasoning: Essays on situated cognition (pp. 361-384). Berlin, Germany: Springer.

Vogel, F., Wecker, C., Kollar, I., \& Fischer, F. (2017). Socio-Cognitive Scaffolding with Computer-Supported Collaboration Scripts: a Meta-Analysis. Educational Psychology Review, 29, 477-511. https://doi-org.datubazes.lanet.lv/10.1007/s10648-016-9361-7

Wang, M. (2010). Online collaboration and offline interaction between students using asynchronous tools in blended learning. Australasian Journal of Educational Technology, 26(6), 830-846.

Weinberger, A., \& Fischer, F. (2006). A framework to analyze argumentative knowledge construction in computer-supported collaborative learning. Computers \& Education, 46, 71-95. https://doi.org/10.1016/j.compedu.2005.04.003

Wu, W., Hsieh, J. S., \& Yang, J. (2017). Creating an Online Learning Community in a Flipped Classroom to Enhance EFL Learners. Oral Proficiency. J. Educ. Technol. Soc., 20, 142-157. 